\title{
JUSTIÇA RESTAURATIVA: \\ O EMPODERAMENTO DOS ENVOLVIDOS A PARTIR DO RECONHECIMENTO
}

\author{
RESTORATIVE JUSTICE: \\ THE EMPOWERMENT OF INVOLVED BY THE RECOGNITION
}

\author{
Carla Maria Franco Lameira Vitale ${ }^{1}$ \\ Luciana Aboim Machado Gonçalves da Silva
}

\section{RESUMO}

A Justiça Restaurativa é uma prática que vem sendo difundida de forma crescente e tem como foco a resolução do conflito de maneira colaborativa, ao privilegiar a participação da vítima, do ofensor e daqueles que, de alguma maneira, interferem no contexto delituoso. Com o objetivo de provocar uma reflexão acerca das possibilidades de restauração, é que se propõe o estudo desse método, contrapondo-o ao atual sistema punitivo. Evidencia-se a questão do reconhecimento como forma de restauração e elevação da sociedade a um patamar de justiça ideal e que deve ser buscada por todos, de maneira a atingir a pacificação social.

Palavras-chave: justiça restaurativa; punição; reconhecimento; conflito; pacificação.

\begin{abstract}
The restorative justice is a practice that has been widespread increasingly and focuses on resolving the conflict collaboratively by privileging the participation of the victim, the offender and those who somehow interfere in the context the criminal environment. In order to cause a reflection about the restorative possibilities, it's proposed the study of this method, comparing it to the current punitive system. Highlights the issue of recognition as a form of restoration and elevation of society to an ideal level of justice and should be pursued by all, in order to achieve social peace.
\end{abstract}

Keywords: restorative justice; punishment; recognition; conflict; pacification.

\footnotetext{
${ }^{1}$ Mestranda em Direito-UFS. Especialista em Direito Penal e Processual Penal-FASE. Graduada em DireitoUNIT. Mediadora e Conciliadora do TJSE. Gestora de Divisão Operacional do Nupemec/TJSE. Instrutora em mediação-CNJ. E-mail: carlamaria.lameira@gmail.com

2 Professora(UFS).Doutora em Direito do Trabalho(USP).Mestre em Direito do Trabalho,especialista em Direito do Trabalho e Processual Civil(PUC/SP).Pós-doutoranda em Direito(UFBA e Università degli studi di Chieti).Vice-Presidente "Asociación Iberoamericana de Derecho de Trabajo". E-mail: lucianags.adv@uol.com.br
} 


\section{INTRODUÇÃO}

A Justiça Restaurativa, como método adequado de solução de conflitos no ambiente punitivo, assume hoje um lugar de destaque no cenário mundial, como forma de promoção da pacificação social.

Trata-se de um método eficaz de acesso à justiça, efetivada pelas próprias partes envolvidas, que são as verdadeiras protagonistas da solução a ser aplicada, com o alcance da justiça de cada um, já que permite o reconhecimento e o restabelecimento de eventuais relações rompidas após o cometimento de um crime.

Dessa forma, busca-se abordar de que maneira a Justiça Restaurativa difere da Justiça Retributiva, no contexto da punição.

O trabalho desenvolvido pelos métodos aplicados pela Justiça Restaurativa poderá ofertar um tratamento apropriado por se diferenciar na abordagem de ações e resultados, já que trata o ambiente de conflito em sua forma mais ampla e alcança a pessoa humana.

Faz-se oportuno, também, estabelecer a conexão entre o empoderamento dos envolvidos, a partir do reconhecimento recíproco proporcionado a partir da prática da Justiça Restaurativa.

Ao analisar a finalidade da pena, no atual sistema retributivo, constata-se que o Código Penal a traz como meio de reprovar o mal produzido pela infração penal praticada, bem como forma de prevenir futuros delitos.

E o desafio que se aponta é demonstrar que dentre os métodos de punição existentes, no ambiente delituoso, a justiça restaurativa desponta como o mais eficaz na obtenção do reconhecimento, por refletir e buscar ações que levam em consideração a pessoa e, consequentemente, a ressocialização eficaz.

Para a realização do presente trabalho, o método utilizado será essencialmente bibliográfico. A origem das informações obtidas partirá de conteúdos extraídos de livros e artigos disponibilizados em revistas e em meio eletrônico sobre a temática da pesquisa, a partir da análise de informações, para que se organize os dados objeto da pesquisa. (GIL, 1999).

O trabalho ora apresentado tem grande relevância jurídica e social, diante da realidade que se apresenta, onde a punição está voltada, principalmente, ao encarceramento, e há que se refletir se a finalidade de ressocialização tem atingido esse objetivo. 


\section{JUSTIÇA RESTAURATIVA VERSUS JUSTIÇA RETRIBUTIVA: ASPECTOS DIFERENCIADORES NO CONTEXTO DA PUNIÇÃO}

Os conflitos são inerentes à existência humana e, desde os primórdios, fazem parte do processo de evolução do homem, sendo imprescindíveis para o desenvolvimento do sistema comunitário.

Os processos de resolução de conflitos foram definidos por Deutsch (1977) como construtivos ou destrutivos. No primeiro, ocorre o fortalecimento da relação social preexistente à demanda; enquanto no segundo, há o rompimento ou enfraquecimento das relações sociais outrora existentes.

É nesse contexto de conflito que se analisará, no âmbito do crime, os modelos da Justiça Restributiva e Justiça Restaurativa e dar-se-á especial atenção às figuras da vítima e do ofensor, que nas palavras de Zerh (2008, p.15):

Compreender a experiência do crime não é tarefa fácil, e nem todos estamos dispostos a empreendê-la. Enfrentar o significado de ser uma vítima ou fazer de outra pessoa uma vítima é algo que desencadeia emoções intensas que, em geral, assustam e nos fazem recuar. A menos que tenhamos vivenciado o crime diretamente, pode ser difícil criar uma empatia total com a situação.

O fato é que vivemos em sociedade e, em face do cometimento de um fato violador da norma penal, surge para o Estado o poder-dever de punir o ofensor. Como afirma Greco (2016, p. 581): "A pena é a consequência natural imposta pelo Estado quando alguém pratica uma infração penal. Quando o agente comete um fato típico, ilícito e culpável, abre-se a possibilidade para o Estado de fazer valer o seu ius puniendi".

Assim, o modelo que prevalece é o do sistema de aplicação de penas em retribuição à violação das regras estabelecidas no ordenamento jurídico, como medida de prevenção de futuras condutas e, ainda, como meio de ressocialização do infrator.

É como dispõe o nosso Estatuto Penal (Brasil, Dec-Lei n. ${ }^{\circ} 2848$ de 07 de dezembro de 1940), nos seguintes termos:

Art. $59 \mathrm{O}$ juiz, atendendo à culpabilidade, aos antecedentes, à conduta social, à personalidade do agente, aos motivos, às circunstâncias e consequências do crime, bem como ao comportamento da vítima, estabelecerá, conforme seja necessário e suficiente para reprovação e prevenção do crime: I - as penas aplicáveis dentre as cominadas; II - a quantidade de pena aplicável, dentro dos limites provistos; III - o regime inicial de cumprimento da pena privativa de liberdade; IV - a substituição da pena privativa da liberdade aplicada, por outra espécie de 
pena, se cabível. (grifo nosso)

Ocorre que esse sistema de reprovação vem sendo questionado, fortemente, pela doutrina, a exemplo do que preconiza Roxin, apud Greco (2016, p.585):

A teoria da retribuição não encontra o sentido da pena na perspectiva de algum fim socialmente útil, senão em que mediante a imposição de um mal merecidamente se retribui, equilibra e expia a culpabilidade do autor pelo fato cometido. Se fala aqui de uma 'teoria absoluta' porque para ela o fim da pena é independente, 'desvinculado' de seu efeito social. A concepção da pena como retribuição compensatória realmente já é conhecida desde a antiguidade e permanece viva na consciência dos profanos com uma certa naturalidade: a pena deve ser justa e isso pressupõe que se corresponda em sua duração e intensidade com a gravidade do delito, que o compense.

Nesses termos, pode-se afirmar que esse viés ressocializador não se concretiza, de maneira que assistimos ao fracasso do sistema penal em vigência, uma vez que o agente criminoso, ao ser submetido ao cárcere, com a sua liberdade cerceada, passa a ser alvo de um processo de dessocialização, que culmina no incentivo ao cometimento de outros delitos.

Na visão de Zerh (2008, p.61), temos que por esse modelo de justiça retributiva há o negligenciamento das lesões e necessidades da vítima e do ofensor, de maneira que "o fenômeno do crime se torna maior do que a vida". Aduz, ainda, que a culpa é a questão central de todo o procedimento penal, o que resulta numa "preocupação com o passado em detrimento do futuro".

É possível estabelecer a premissa de que a pena deve ser reconhecida como um castigo justo e a nossa sociedade aplaude esse espetáculo de punição e de dor, referendado pelo clamor midático de se buscar penas cada vez mais severas e passíveis de sofrimento em retribuição ao mal causado.

Interessa pontuar que, Mathiesen (1972), apud Carvalho (2002, p.133), propõe um modelo desconstrutor do atual modelo penal, no que concerne às formas de apoio às vítimas, que devem se sobrepor ao anseio de aumento de punição do transgressor, já que aquelas não recebem nenhum apoio do atual sistema.

Da mesma forma, Christie (1984), apud Carvalho (2002, p.137), ao evidenciar que "o sistema penal e, principalmente, a pena, são estruturas de controle social encarregadas de produzir sofrimento e impor dor", propõe como solução, a composição de estruturas de justiça participativa e afirma que quando o Estado assume o conflito, há uma nova vitimização do sujeito passivo, já que este não participa da resolução do caso. Propõe, ainda, o tratamento 
processual igualitário entre ofensor e vítima, atribuindo-lhe capacidade de negociar no que concerne à compensação pelo injusto cometido.

É para contrapor essa perspectiva que o ideal da justiça restaurativa se apresenta hoje como método adequado de solução de conflitos no ambiente punitivo.

Nesse toar, convém ressaltar os princípios defendidos pela abordagem restaurativa, trazidos por Zehr (2012, p. 31), ao analisar o comportamento nocivo: "O crime é uma violação de pessoas e relacionamentos interpessoais; As violações acarretam obrigações; A principal obrigação é corrigir o mal praticado".

Esses princípios básicos são enunciados na Resolução do Conselho Econômico e Social das Nações Unidas, de 13 de agosto de 2002.

Oportuno introduzir o conceito de Justiça Restaurativa, ainda conforme dispõe Zehr (2012, p. 49):

Justiça Restaurativa é um processo para envolver, tanto quanto possível, todos aqueles que têm interesse em determinada ofensa, num processo que coletivamente identifica e trata os danos, necessidades e obrigações decorrentes da ofensa, a fim de promover o restabelecimento das pessoas e endireitar as coisas, na medida do possível.

Para Pinto (2005, p. 20):

A Justiça Restaurativa baseia-se num procedimento de consenso, em que a vítima e o infrator, e, quando apropriado, outras pessoas ou membros da comunidade afetados pelo crime, como sujeitos centrais, participam coletiva e ativamente na construção de soluções para a cura das feridas, dos traumas e perdas causados pelo crime.

Como se vê, a Justiça Restaurativa propõe o tratamento do conflito de forma diferenciada, transformando-o em busca da construção da paz.

A partir das características traçadas sobre os modelos de justiça penal ora em comento, Zehr (2008, p. 198) afirma que "se há lugar para punição na abordagem restaurativa, ela não deve ser um lugar central. A punição precisaria ser aplicada sob condições em que o nível de dor é controlado e reduzido, a fim de manter a restauração e cura como objetivos". Finaliza sintetizando, através de lentes retributiva e restaurativa, as duas perspectivas:

Segundo a justiça retributiva: 1. o crime viola o Estado e suas leis; 2. o foco da justiça é o estabelecimento da culpa 3. para que se possa administrar doses de dor; 4. a justiça é buscada através de um conflito entre adversários 5. no qual o ofensor está contra o Estado; 6. regras e intenções valem mais que os resultados; 6. um lado ganha e o outro perde. 
Segundo a justiça restaurativa: 1 o crime viola pessoas e relacionamentos; 2. a justiça visa identificar necessidades e obrigações 3. para que a coisas fiquem bem; 4. a justiça fomenta o diálogo e o entendimento mútuo; 5. dá às vítimas e ofensores papeis principais; 6. é avaliada pela medida em que responsabilidades foram assumidas, necessidades atendidas, e cura (de indivíduos e relacionamentos) promovida.

Pelo que se pode depreender, na Justiça Restaurativa, a participação dos envolvidos é privilegiada, uma vez que são os verdadeiros protagonistas da melhor solução a ser encontrada. O foco da retribuição é o passado, com atribuição de culpa, ignorando-se a vítima; já no contexto da restauração, o foco é o futuro, em busca da solução do problema a ser construída, atribuindo-se à vítima um papel ativo, com ênfase nas suas necessidades.

Vasconcelos (2008, p. 126) traz como exemplos de processos restaurativos, a mediação, a conciliação, as conferências e os círculos e ressalta que os acordos obtidos nesses procedimentos teriam sempre "o fim de atender as necessidades individuais e coletivas de todas as partes, bem como de demarcar as suas responsabilidades, visando à reintegração da vítima e do ofensor".

De forma similar, Azevedo (2005, p. 135) cita como processos que pertencem à Justiça Restaurativa: "a mediação vítima-ofensor (Victim Offender Mediation), a conferência (conferencing), os círculos de pacificação (peacemaking circles), círculos decisórios (sentencing circles), a restituição (restitution), entre outros" e ressalta o enfoque voltado aos direitos humanos ao reafirmar a responsabilidade de ofensores pelos atos cometidos, bem como por proporcionar a reinserção destes na comunidade da qual fazem parte.

Evidencia esse autor que, em todos os casos, enfatiza-se as necessidades da vítima, da comunidade e do ofensor, o que atende de forma direta aos preceitos reintegrativos que a modalidade restaurativa propõe.

Quem bem define esses modelos restaurativos é Zehr (2012, p. 58 e 62) ao explicar que: Os encontros vítima e ofensor envolvem basicamente vítimas e ofensores. Nos casos em que for indicado, trabalhase com a vítima e o ofensor em separado e, depois, havendo consentimento para que continue o processo, acontece um encontro ou diálogo entre os dois, organizado e conduzido por um facilitador treinado que orienta o processo de maneira equilibrada. (...) Membros da família da vítima e do ofensor poderão participar, mas normalmente essas pessoas têm papéis de apoio secundários. [...]

Na prática das conferências de grupos familiares temos a ampliação do círculo básico de participantes, que passa a incluir os familiares de outras pessoas significativas para as partes diretamente envolvidas. Esse modelo vem se concentrando no apoio ao ofensor, para que ele assuma a responsabilidade e mude seu comportamento, e por isso a família do ofensor e/ou pessoas relevantes da comunidade são muito importantes, [...]

Os círculos ampliam intencionalmente o rol de seus participantes. Vítimas, ofensores, familiares, e às vezes profissionais do judiciário são incluídos, mas os membros da comunidade são partes essenciais. Eles podem ser 
convidados em função da sua ligação ou interesse em uma infração específica, ou por iniciativa da vítima ou do ofensor.

Pranis (2011, p. 09) aprofunda o conceito do modelo circular com muita propriedade, ao discorrer:

O círculo é um processo de diálogo que trabalha intencionalmente a criação de um espaço seguro para discutir problemas muito difíceis ou dolorosos, a fim de melhorar os relacionamentos e resolver diferenças. A intenção do círculo é encontrar soluções que sirvam para cada membro participante. O processo está baseado na suposição de que cada participante do círculo tem igual valor e dignidade, dando então voz igual a todos os participantes. Cada participante tem dons a oferecer na busca para encontrar uma boa solução para o problema.

Pretende-se, portanto, com os modelos utilizados pela justiça restaurativa, resolver o conflito e todas as suas possíveis ramificações. A ideia é que as partes pensem nas possibilidades de soluções e, dentre elas, a que melhor atende aos interesses de todos os envolvidos.

\section{RECONHECIMENTO E RESTAURAÇÃO NO ÂMBITO DA JUSTIÇA PENAL}

É imprescindível a análise do reconhecimento no contexto de conflito presente no âmbito da justiça penal.

$\mathrm{Na}$ análise do reconhecimento destaca-se o filósofo e sociólogo alemão Axel Honneth, atual representante da tradição da teoria crítica da Escola de Frankfurt, que em sua obra "Luta por Reconhecimento. A Gramática moral dos conflitos sociais" faz uma análise evolutiva do processo do reconhecimento.

Honneth (2003) parte da ideia defendida pelo filósofo Hegel, sobre "reconhecimento" utilizado em seus escritos de Jena, e o recontextualiza através da psicologia social de Georg Mead, de maneira a investigar a importância das normas morais nas relações humanas.

A ideia original de Hegel, tazida por Honneth (2003, p. 29), sobre dominação política, assim é exposta:

Hegel defende naquela época a convicção de que resulta de uma luta dos sujeitos pelo reconhecimento recíproco de sua identidade uma pressão intrassocial para o estabelecimento prático e político de instituições garantidoras da liberdade; trata-se da pretensão dos indivíduos ao reconhecimento intersubjetivo de sua identidade, inerente à vida social desde o começo na qualidade de uma tensão moral que volta a impelir para além da respectiva medida institucionalizada de progresso social e, desse modo, conduz pouco a pouco a um estado de liberdade comunicativamente vivida, pelo caminho negativo de um conflito a se repetir de maneira gradativa. 
Aduz o mesmo autor que essa "luta por reconhecimento" trazida por Hegel ganhou contornos materialistas através da psicologia social de Mead.

Tanto Hegel, quanto Mead, conforme explica Honneth (2003, p. 156), utilizam, para justificar as formas de reconhecimento recíproco, a tripartição das relações sociais em: relações amorosas, relações jurídicas e relações de estima social.

Para Honneth (2003) essa tripartição necessita de uma justificativa que vai mais além e propõe, em sua teoria, a correspondência com três formas de reconhecimento recíproco, que são: a dedicação emotiva (amor), o reconhecimento jurídico (relação jurídica) e o assentimento solidário (estima social).

Baseado nos ideais de Donald Woods Winnicott, Honneth (2003) prossegue relacionando as categorias da seguinte forma: a dedicação emotiva (amor) com a dependência absoluta, a qual ocorre durante o desenvolvimento primário do indivíduo, geralmente até os seis meses de idade, responsável pela capacidade de autoconfiança e como base das relações sociais entre adultos. De forma contínua, a relação jurídica trata do reconhecimento recíproco dos sujeitos como portadores de direitos e como seres capazes de decidir com autonomia individual sobre normas morais, o que é traduzido como autorrespeito. E, por último, a estima social baseia-se numa comunidade de valores focada na solidariedade.

Dessa forma, Honneth (2003) conclui afirmando que o indivíduo pertence a uma rede de relações intersubjetivas, de forma que depende estruturalmente do reconhecimento dos outros indivíduos.

Nesses termos, é possível afirmar que, em havendo desrespeito a esses preceitos, surge o incentivo de se lutar pelo reconhecimento, o que será superado apenas quando o indivíduo estiver apto a ser inserido na sociedade de forma ativa e sadia.

Com base no que foi exposto, chega-se a seguinte indagação: O direito penal promove o reconhecimento?

Não se pode deixar de citar Hulsman (1993) quando este afirma que é extremamente difícil falar de legitimidade da pena em situações onde não há relação entre aquele que pune e aquele que é punido, bem como quando se depara com ausência de reconhecimento da autoridade. Aduz que só se pode falar em pena justa, se a autoridade de quem pune for totalmente aceita. Hulsman refere-se ao sistema penal como uma organização estatal investida do poder de produzir um mal sem que sejam ouvidas as pessoas interessadas.

Ao se referir ao atual modelo de pena privativa de liberdade, Hulsman (1993, p. 62) assim se manifesta: 
(...) o condenado à prisão penetra num universo alienante, onde todas as relações são deformadas. A prisão representa muito mais do que a privação de liberdade com todas as suas sequelas. Ela não é a retirada do mundo normal da atividade e do afeto; a prisão é, também e principalmente, a entrada num universo artificial onde tudo é negativo. Eis o que faz da prisão um mal social específico: ela é um sofrimento estéril.

Oportunos os questionamentos feitos por Greco (2016, p.588) ao analisar o atual sistema penal: "Em um sistema penitenciário falido, como faremos para reinserir o condenado na sociedade da qual ele fora retirado pelo Estado? Será que a pena cumpre, efetivamente, esse efeito ressocializante ou, ao contrário, acaba de corromper a personalidade do agente?"

Na opinião de Zehr (2008, p. 145):

Nosso sistema jurídico define as ofensas como violações das normas, das leis. Definimos o Estado como vítima. Em termos bíblicos, entretanto, o mal não é uma violação de regras, mas uma violação do bom relacionamento. As vítimas são as pessoas e os relacionamentos, e não as regras ou governos ou a ordem moral.

Assim, do que foi exposto, é possível concluir que o atual sistema retributivo de punição não promove o reconhecimento dos envolvidos no contex to da infração penal, uma vez que se privilegia a discussão da culpa, em detrimento da busca de soluções; o crime é visto como violação da lei, ao invés de violador das relações sociais; preocupa-se em posicionar o Estado como vítima, e não há o cuidado de se trabalhar necessidades e sentimentos das vítimas.

Nesse sentido, o modelo de justiça restaurativa pode ser visto como o sistema que promove, efetivamente, o reconhecimento dos indivíduos por tratar todos os envolvidos no contexto infracional como partes importantes no processo.

E como afirma Zehr (2008, p. 190): "A responsabilização é multidimensional e transformadora".

\section{O EMPODERAMENTO DOS ENVOLVIDOS A PARTIR DO RECONHECIMENTO}

É imperioso analisar o crime sob um enfoque positivo, que promove o desenvolvimento da democracia, a partir de uma perspectiva individual, de forma a educar a sociedade para que, empoderada e consciente de sua capacidade de resolver seus próprios conflitos, possa restabelecer o convívio harmônico. 
O modelo de justiça restaurativa deve ser vista como processo apto a promover a integração dos indivíduos, através do estímulo ao diálogo para a construção conjunta do consenso.

O aprofundamento no estudo do empoderamento, inclusive sob o enfoque dado ao reconhecimento, mostra-se salutar para que possamos entender que a comunidade tem um papel importante a desempenhar.

Como analisa Zehr (2008, p. 192):

O primeiro passo na justiça restaurativa é atender às necessidades imediatas, especialmente as da vítima. Depois disso, a justiça restaurativa deveria buscar identificar necessidades e obrigações mais amplas. Para tanto o processo deverá, na medida do possível, colocar o poder e a responsabilidade nas mãos dos diretamente envolvidos: a vítima e o ofensor. Deve haver espaço também para o envolvimento da comunidade. Em segundo lugar, ela deve tratar do relacionamento vítima-ofensor, facilitando sua interação e a troca de informações sobre o acontecido, sobre cada um dos envolvidos e sobre suas necessidades. Em terceiro lugar, ela deve se concentrar na resolução dos problemas, tratando não apenas das necessidades presentes, mas das intenções futuras.

O mesmo autor rechaça esse entendimento ao evidenciar que "o empoderamento tornase crucial para que haja recuperação e justiça". E, como consequência, ao ofensor é garantida a responsabilidade e a conclusão do procedimento quando participa de forma ativa da solução construída pelos envolvidos. (ZEHR, 2008, p. 192)

Faz-se conveniente, estabelecer a conexão entre o empoderamento dos envolvidos a partir do reconhecimento. E para ilustrar essa vinculação pode-se utilizar o exemplo trazido por Pinto (2007, p. 405):

Em 1995, quando a África do Sul pós-apartheid estabeleceu a Comissão de Verdade e Reconciliação, recebeu duras críticas dos ativistas ocidentais por oferecer anistia aos agentes da opressão. Todavia, os procedimentos foram baseados na ideia de justiça restaurativa e não retributiva. Apesar da anistia, o reconhecimento da verdade e a rejeição social dos atos cometidos, funcionaram como um processo de reprovação moral. $\mathrm{O}$ arcebisbo anglicano Desmond Tutu, um dos maiores defensores das comissões de verdade e da justiça restaurativa, ressaltou que esta visão é baseada não só em ideias cristãs de perdão para aqueles que reconhecem seus erros como também no conceito indígena de ubuntu.

A definição de ubuntu, desenvolvida por Tutu, está ligada à busca por harmonia social. Em suas palavras, "um ser humano só é um ser humano por meio de outros e, se um deles é humilhado ou diminuído, o outro o será igualmente"(TUTU, 2000, p.35, tradução minha). É a ideia de compartilhamento, de pertencimento a uma comunidade. 
É essa a ideia de pertencimento, afirmada por Honneth (2003), conforme já pontuado no capítulo anterior, que traduz o verdadeiro sentido de reconhecimento, ao posicionar os indivíduos numa rede de relações intersubjetivas e dependentes do reconhecimento dos outros indivíduos.

Interessante pontuar o que Hulsman (1993, p. 32) expõe sobre sua experiência de vida ao ressaltar que suportou muito melhor o período de detenção, como preso político, do que os anos em que os seus pais o colocaram num internato, em tese, para o seu bem:

O preso político não perde a autoestima nem a estima dos outros. Ele sofre em todas as dimensões de sua vida, mas permanece um homem que pode olhar de frente. Não está diminuído. Esta experiência foi fundamental para mim, ao mostrar a importância de não ser estigmatizado quando se é colocado à margem.

Esse pensamento retrata a questão do reconhecimento proveniente da estima social, descrita por Honneth (2003), conforme já citado, baseado nos valores da comunidade.

Dessa forma, constata-se que o reconhecimento promove o empoderamento necessário para que o envolvido no contexto infracional, sinta-se capaz e apto para participar ativamente do resultado a ser buscado através do modelo restaurativo.

Ressalte-se que, como já dito, a solução obtida através dos métodos utilizados pela prática restaurativa, a exemplo da mediação, promove o reconhecimento recíproco dos envolvidos, ao tratá-los como partes integrantes do processo e com a mesma importância na construção do consenso.

Conforme evidenciado por Azevedo (2013, p. 171), no Manual de Mediação Judicial, um outro objetivo, que se destaca através desse método, é o incentivo dado pelo mediador aos envolvidos, para que estes ganhem autonomia, ao terem consciência de sua capacidade de resolver seus próprios conflitos. Esse objetivo está vinculado ao conceito de empoderamento, que consiste em fazer com que a parte, após contato com as técnicas utilizadas e estímulo à comunicação, sinta que pode gerir seus próprios conflitos.

É o que destaca Luciana Aboim Silva (2013, p. 163), quando explica que as pessoas se acostumaram a confiar a um terceiro imparcial as decisões sobre suas desavenças, como se fossem menos capazes de, por si sós, promoverem a justiça no caso concreto. E pontua:

(...) o procedimento de mediação, que enfatiza a cooperação ao invés do confronto, é pautado na identificação das reais motivações das partes, de sorte a transparecer os sentimentos e interesses subjacentes ao conflito, possibilitando os dissidentes chegarem a um acordo em uma dimensão ampla da problemática(...) 
No mesmo sentido entende Pranis (2011, p. 25), ao tratar do método circular:

O comprometimento do círculo para criar relacionamentos antes de discutir o problema central é uma parte muito importante do processo circular. Os círculos retardam, de maneira deliberada, o diálogo sobre os problemas contenciosos, até que o grupo tenha trabalhado um tanto em construção de relacionamentos.

Pranis (2011, p. 39) também evidencia a questão do empoderamento ao explicar que:

Os participantes de um círculo desempenham um papel principal na projeção de seu próprio espaço de duas maneiras. Primeiro, discutindo os valores que são importantes para eles e para aqueles que eles querem trazer para o diálogo. Lançam o alicerce do espaço do círculo com os valores. Segundo, os participantes trabalham juntos para definir as diretrizes para sua discussão. [...] Os participantes elaboram as diretrizes juntos, concordam com elas conjuntamente e então apoiam-se mutuamente para observá-las no decorrer do círculo.

Então, percebe-se que a abordagem restaurativa, através do reconhecimento recíproco dos envolvidos como partes integrantes da melhor solução a ser trabalhada, os empodera e pode ser tratada como método eficaz de transformação social, por oferecer um sistema de valores positivos e harmônicos, que regulam as normas de boa convivência, e evidencia a importância dos relacionamentos.

Zehr (2008, p. 196) finaliza esclarecendo que: "Os ideais de empoderamento e interação direta entre vítima e ofensor nem sempre podem ser atingidos. Algumas decisões por terceiros são inevitáveis". Refere-se a casos muito graves para a comunidade e que não se recomenda ser trabalhado pela vítima e pelo ofensor. Ressalta que a comunidade deve supervisionar, mas salienta que esses casos não são a regra e que, por isso, mesmo nesses casos, deve-se prestar atenção na natureza verdadeira do crime e do ideal a ser buscado.

\section{CONCLUSÃO}

A Justiça Restaurativa apresenta-se como um novo modelo de Justiça Penal, que surge em contraposição à tradicional Justiça Retributiva, e tem como objetivo suprir as deficiências do sistema punitivo.

Temos que o Direito Penal, ao primar pelo convívio pacífico da sociedade, delega ao Estado a obrigação de prevenir e reprimir aqueles que violam a lei e cometem o fato delituoso. À pena é confiada a função ressocializadora, porém questiona-se a forma de punição baseada, 
sobretudo, na privação de liberdade, a qual impede que o indíviduo tenha a sua dignidade preservada e possa retornar ao convívio social reabilitado.

Faz-se oportuna a análise do reconhecimento sob a perspectiva desenvolvida por Axel Honneth, a partir de uma visão filosófica Hegeliana, atualizada por Geog Mead, que resulta na tese de haver três as formas de reconhecimento: o amor, o direito e a solidariedade, os quais se relacionam com a autoconfiança, autorrespeito e autoestima.

Sustenta Honneth, que cada forma de reconhecimento é passível de sofrer uma violação, um desrespeito, que culmina em um reconhecimento recusado.

Nesse contexto, Honneth conclui que os movimentos de luta social são fruto dessa recusa e demonstra que os indivíduos pertencem a uma rede de relações subjetivas de reconhecimento recíproco. Aduz que esse sentimento de violação só pode ser superado quando lhes é permitida a participação efetiva na sociedade.

Sob essa análise, conclui-se que o atual sistema retributivo de punição não promove esse reconhecimento, uma vez que se baseia tão somente na discussão da culpa e no fato ocorrido e à vítima é assegurado um papel secundário, onde suas lesões e necessidades são negligencadas durante todo o processo criminal. Ao ofensor é atribuído o "justo castigo" e a este também não é permitida a análise subjetiva de sua conduta.

O modelo restaurativo, ao contrário, parte do pressuposto de que todos os envolvidos no contexto fático do delito devem participar ativamente da construção de um consenso. A vítima, o ofensor e até mesmo outras pessoas ou membros da comunidade são considerados protagonistas, já que afetados pelas perdas e abalos sofridos com o evento danoso.

Ressalte-se que através dos métodos defendidos pela justiça restaurativas, a exemplo da mediação e dos círculos restaurativos, enfatiza-se a importância da comunicação, a qual assume ainda maior relevância em contextos, nos quais interesses e necessidades precisam ser trabalhados, de maneira a se atingir o reconhecimento recíproco entre os indivíduos.

A ideia é empoderar os envolvidos, para que se sintam aptos e capazes de pensar na melhor solução a ser construída e que atenda a justiça de cada um. Aos ofensores é dada a chance de mostrar a sua verdadeira face, e à vítima e aos membros da comunidade é permitido que demonstrem as consequências advindas dos danos sofridos, de modo que possa haver o reconhecimento de uns pelos outros, essencial para que se construa um caminho a ser trilhado.

É preciso que questionemos, de forma contínua, o nosso modelo de justiça, essencialmente retributivo, a fim de que as mudanças que já vêm ocorrendo com a prática restaurativa sejam difundidas cada vez mais e que se possa ultrapassar esse paradigma e, dessa 
forma, contribuir para a pacificação social, através do reconhecimento de que todos fazem parte de uma rede de relacionamentos, onde o comportamento de um interfere no do outro. E como afirma Zehr (2002, p. 265): "Talvez, portanto, a justiça restaurativa de fato sugira um modo de vida".

\section{REFERÊNCIAS:}

AZEVEDO, André Gomma de (Org.). Manual de mediação judicial. Brasília, DF: Ministério da Justiça e Programa das Nações Unidas para o Desenvolvimento (PNUD), 2013.

O Componente de Mediação Vítima Ofensor na Justiça Restaurativa: Uma Breve Apresentação de uma Inovação Epistemológica na Autocomposição Penal. In: PINTO, Renato Sócrates Gomes; SLAKMON, Catherine e DE VITTO, Renato Campos Pinto (Org). Justiça Restaurativa. Brasília, DF: Ministério da Justiça e Programa das Nações Unidas para o Desenvolvimento (PNUD), 2005. p. 135-150.

BOYES-WATSON, Carolyn; PRANIS, Kay. No Coração da Esperança. Guia de Práticas Circulares. $O$ uso de círculos de construção de paz para desenvolver a inteligência emocional, promover a cura e construir relacionamentos saudáveis. Centro de Justiça Restaurativa da Suffolk University. Trad. Fátima De Bastiani. Porto Alegre: Tribunal de Justiça do Estado do Rio Grande do Sul, Departamento de Artes Gráficas, 2011.

BRASIL. Decreto-Lei n. ${ }^{\circ}$ 2.848, de 07 de dezembro de 1940. Disponível em: < http://www.planalto.gov.br/ccivil 03/decreto-lei/Del2848compilado.htm>. Acesso em: 01 jul. 2016.

CARVALHO, Salo de. Considerações sobre as Incongruências da Justiça Penal Consensual: retórica garantista, prática abolicionista. In: ; WUNDERLICH, Alexandre (Org.). Diálogos sobre a Justiça Dialogal. Teses e Antíteses sobre os Processos de Informalização e Privatização da Justiça Penal. Rio de Janeiro: Ed. Lumen Juris, 2002. p. 129-157.

GIL, Antônio. C. Métodos e técnicas de pesquisa social. São Paulo: Atlas, 1999.

GRECO, Rogério. Curso de Direito Penal. Parte Geral. Rio de Janeiro: Ed. Impetus, 2016. 
HONNETH, Axel. Luta por Reconhecimento. A Gramática moral dos conflitos sociais. Trad. Luiz Repa. Rio de Janeiro: Editora 34, 2003.

HOUAiss, A. Dicionário Houaiss da Língua Portuguesa. Rio de Janeiro: Rev. Objetiva, 2004.

HUlSMAN, Louk; CELIS, Jacqueline Bernat de. Penas Perdidas. O Sistema Penal em Questão. Trad. Maria Lúcia Karam. Rio de Janeiro: Luam Editora, 1993.

MOORE, Cristopher W. O Processo de Mediação: estratégias práticas para a resolução de conflitos. Trad. Magda França Lopes - 2 edição - Porto Alegre: Ed. Artmed, 1999.

PINTO, Renato Sócrates Gomes. Justiça Restaurativa é Possível no Brasil? In: SLAKMON, Catherine e DE VITTO, Renato Campos Pinto (Org). Justiça Restaurativa. Brasília, DF: Ministério da Justiça e Programa das Nações Unidas para o Desenvolvimento (PNUD), 2005.

PINTO, Simone Martins Rodrigues. Justiça Transicional na África do Sul: Restaurando o Passado, Construindo o Futuro. Rio de Janeiro, vol.29, n. ${ }^{\circ}$ 2, julho/dezembro 2007, p. 393-421.

PRANIS, Kay. Círculos de Justiça Restaurativa e de Construção da Paz: guia do facilitador. Trad. Fátima De Bastiani. Porto Alegre: Tribunal de Justiça do Estado do Rio Grande do Sul, Departamento de Artes Gráficas, 2011.

SILVA, Luciana Aboim Machado Gonçalves da. Mediação interdisciplinar de conflitos: mecanismo apropriado para resolução de conflitos familiares. In: (Org). Mediação de Conflitos. São Paulo: Ed. Atlas, 2013. p. 160-180.

VASCONCELOS, Carlos Eduardo. Mediação de Conflitos e Práticas Restaurativas. São Paulo: Ed. Método, 2008.

ZEHR, Howard. Trocando as Lentes. Um novo foco sobre o crime e a Justiça Restaurativa. Trad. Tônia Van Acker. São Paulo: Palas Athena, 2003. 